UDC 091

LBC 87.3

\title{
PHILOSOPHICAL UNDERSTANDING OF THE DIALOGUE OF CULTURES IN THE CONCEPTS OF M.M. BAKHTIN AND V.S. BIBLER
}

\author{
Anastasia A. Volkova \\ "Universarium" Distance Education Inter-University Platform, Moscow, Russian Federation; \\ Peoples Friendship University of Russia, Moscow, Russian Federation
}

\begin{abstract}
Dialogue as a complex creative interaction and mutual influence of various cultural and value consciousnesses is now considered as the basis of cultural existence, and the dialogue of cultures has become a key concept of modern philosophy. Dialogue in a philosophical context is an informative and existential communicative interaction between different parties, the purpose of which is to achieve understanding. The basis of Dialogic philosophy, first of all, is the recognition that the individual is formed and realized in communication. In order to become a subject of history and a subject of knowledge, he must enter into a dialogue with himself, another individual, God, nature. At present, the subjects of the dialogue are not only different individuals, but also entire ethnic groups, cultures, and civilizations, thereby expanding the functioning of the dialogue to a means of developing intercultural, interethnic and intercivilizational relations and emphasizing the commonality of the world historical process and the cultural heritage of mankind. The article is devoted to the comparative analysis of two theories of the dialogue of cultures: M.M. Bakhtin and his follower V.S. Bibler. By developing and deepening each other's ideas, they enter into a non-spatial and timeless dialogue and create a unified teaching about the ongoing interaction and continuity of cultures and intercultural communication. The General idea of the dialogue unites the philosophical concepts of Bakhtin and Bibler, but The latter, based on the theory of Bakhtin and expanding its ideas, created his own original concept of solving the most important problems of philosophical thought. Thinkers reflected the most important historical and philosophical phenomenon - the possibility of intercultural dialogue as a consequence of self-knowledge and the ability to relate themselves to Other.
\end{abstract}

Key words: dialogue of cultures, text, intercultural communication, M.M. Bakhtin, V.S. Bibler.

УДК 091

ББК 87.3

\section{ФИЛОСОФСКОЕ ПОНИМАНИЕ ДИАЛОГА КУЛЬТУР В КОНЦЕПЦИЯХ М.М. БАХТИНА И В.С. БИБЛЕРА: СРАВНИТЕЛЬНЫЙ АНАЛИЗ}

\author{
Анастасия Алексеевна Волкова \\ Дистанционная образовательная межуниверситетская площадка «Универсариум», \\ г. Москва, Российская Федерация; \\ Российский университет дружбы народов, г. Москва, Российская Федерация
}


субъектом познания, ему необходимо вступить в диалог с самим собой, другим индивидом, Богом, природой. В настоящее время субъектами диалога становятся не только различные личности, но и целые этносы, культуры, цивилизации, тем самым расширяя функционирование диалога до средства развития межкультурных, межэтнических и межцивилизационных отношений и подчеркивая общность мирового исторического процесса и культурного наследия человечества. Статья посвящена исследованию теорий диалога культур М.М. Бахтина и его последователя В.С. Библера. Развивая и углубляя идеи друг друга, они вступают во внепространственный и вневременной диалог и создают единое учение о непрекращающемся взаимодействии и преемственности культур и межкультурной коммуникации. Общая идея диалога объединяет философские концепции М.М. Бахтина и В.С. Библера, однако последний, основываясь на теории Бахтина и развивая ее идеи, создал собственную оригинальную концепцию решения центральных проблем философии диалога. Мыслители концептуализировали важнейший историко-философский феномен - межкультурный диалог - и показали его возможности для самопознания и взаимодействия с другими людьми.

Ключевые слова: диалог культур, текст, межкультурная коммуникация, М.М. Бахтин, В.С. Библер.

Мне казалось, что с моей кожей граничит элемент самой жизненности, нечто, что было не я, совсем не я, совсем не привычное я, а ощутимое другое, не просто нечто другое, а действительно само Другое; и оно все-таки допускало меня к себе, доверялось мне, просто общалось со мной, как Ты и Ты.

М. Бубер

К середине XX в. в философском знании закрепилась идея диалога культур, проблемное поле которой расширяется и поныне. Само понятие диалога изменялось на протяжении прошлого столетия, прирастая новыми смыслами и меняя свое внутреннее содержание от понимания его как обычного обмена информацией до сложного творческого взаимодействия и взаимовлияния различных культурноценностных сознаний. В философском контексте диалог является информативным и экзистенциальным коммуникативным взаимодействием между различными сторонами, целью которого является достижение понимания.

Основой диалогической философии является признание того, что индивид формируется и реализуется в общении. Чтобы стать субъектом истории и субъектом познания, ему необходимо вступить в диалог с самим собой, другим индивидом, Богом, природой. Основой же познавательной деятельности человечества выступает уже не монологическое абстрактно-логическое мышление, а имеющее диалогическую природу практическое и речевое, которое направлено на взаимодействие с другими людьми.
В настоящее время диалог является предметом исследований не только философии, но и таких областей знаний, как культурология, лингвистика, литературоведение, социология, психология, педагогика, и прочих. Субъектами диалога становятся не только различные личности, но и целые этносы, культуры, цивилизации. Тем самым расширяется функционирование диалога до средства развития межкультурных, межэтнических и межцивилизационных отношений и подчеркивается общность мирового исторического процесса и культурного наследия человечества.

Теперь диалог рассматривается как некий механизм культурного бытия, его основа, ибо бытие само по себе диалогично. Диалог культур же стал ключевым понятием современной философской мысли.

Обращение к диалогу в XX в. не случайно: он привлекает внимание философов, начиная еще с античных времен. Яркие примеры общения двух и более исторических или выдуманных персонажей мы встречаем в диалогах Платона. В их спорах рождается истина. В средневековом диспуте, который заменяет диалог схоластическим спором, также обнаруживаются зачатки диалогической тенденции. B XVIII в. Д. Дидро выявляет противоречия мышления с помощью диалогических построений, а Л.А. Фейербах в XIX в. пытается осмыслить отношения Я и Ты («другое Я»).

B XVII-XX вв. происходило активное развитие науки как главной формы духовной жизни человека и культуры, именно поэтому господствующим философским направлением этого времени считается рационалистская гносеология. Научный прогресс рассматривался как основа развития личности и общества. 


\section{НАУЧНЫЕ СООБЩЕНИЯ}

В основание научной методологии было положено субъект-объектное отношение, при котором субъект определялся исключительно в контексте познания, а объект представлял интерес только с точки зрения совокупности его свойств, важных для анализа и обогащения опыта и познающего разума.

Начало XX в. стало сложным и переломным периодом для человечества. Осмысление результатов Первой и Второй мировых войн способствовали оборачиванию человеческого сознания на себя, к изучению своей сущности и бытия, что вывело на первый план рефлексивные методы познания. Этот антропологический поворот отразился и в философской мысли, в частности, в работах таких исследователей, как Э. Левинас, М. Бубер, М.М. Бахтин, В.С. Библер, Ю.М. Лотман. Размышления в данном ключе привели к появлению в философском дискурсе XX в. особого направления теоретических исследований - философии диалога.

Идеи представителей нового направления основывались на богатой античной культурной традиции, экзистенциализме, герменевтике, а также опирались на другие философские течения прошлого столетия, в центре рассмотрения которых была коммуникация, понимаемая как общение двух равноправных субъектов, основывающееся на взаимопонимании. Методологическая основа исследований диалогизма составила альтернативу субъектно-объектным отношениям, где иной - всегда объект. Таким образом, философия диалога осуществила попытку отказа от моделей, которые построены на бинарных оппозициях и где Я является центром. Теперь главным становится общение Я с Другим, так как именно эта встреча позволяет выйти за собственные границы и преодолеть замкнутость.

Рассуждая на тему Другого, Эммануэль Левинас утверждал, что основная идея «заключается в том, чтобы настаивать на первичности бытия ради другого» [Левинас 2006, 179]. Преодолевая феноменологический тупик в отношении другого, Левинас высказывает мысль, что единственной возможной формой трансцендентального является диалог, а Другой для Я становится уникальным мыслимым гарантом Я. Однако в модели Левинаса также присутствуют некие «Третий» и «Четвертый», то есть общество, которое делает нереализуемой ситуацию встречи Я и Другого, свобода которого безусловна и абсолютна. Именно общество диктует требования сравнения и выбора между всеми «другими» по критерию наибольшей нужды в поддержке. Такой выбор можно совершить только опираясь на этический принцип.

В предлагаемой Левинасом модели диалога Я и Другой выступают как отдельные друг от друга субъекты, с одной стороны, тождественные, а с другой - абсолютно разные. Именно это является важным условием осуществления любого диалога: с одной стороны, Я всегда замкнут на себе, с другой - в Я должно быть включено существование Другого. Вступая в коммуникативное взаимодействие, Я и Другой избавляются от качественного бытия личностей и воссоздают друг друга в диалоге благодаря языку: «Языковое выражение предполагает существование трансценденции, радикального разделения, чуждости друг другу собеседников, обнаружение Другого перед иным Я» [Левинас 2000, 106]. И, несмотря на явные различия между Я и Другим, говорят они на одном языке.

Совершенно в другом ключе рассматривают проблему Другого экзистенциалисты. В отличие от принятой Э. Гуссерлем интерпретации Другого как безусловного феномена сознания Я, в экзистенциалистском ключе Другой предстает как Чужой (или чуждый Я). Об этом в книге «Бытие и ничто» говорит Ж.-П. Сартр: «Присутствие Другого для меня и меня для Другого есть объективность» [Сартр 2000, 238]. Другими словами, Я становится объектом рассмотрения для Другого, который таким образом вторгается в мир и сознание Я, отчуждая их себе.

К проблеме диалога и отношений Я и Другого обращались многие исследователи, начиная с античных времен, но пионерами и основоположниками в области теории диалога и особенно диалога культур в отечественной и западной философской мысли являются М.М. Бахтин и его последователь В.С. Библер. Вступая во вневременной и внепространственный диалог, развивая и углубляя идеи друг друга, они создали единое учение о непрекращающемся взаимодействии и преемственности культур в процессе межкультурной коммуникации. 


\section{О концепции диалога}

\section{М.М. Бахтина}

Когда диалог кончается, все кончается. Поэтому диалог, в сущности, не может и не должен кончиться

М.М. Бахтин

Творческое наследие М.М. Бахтина необыкновенно полифонично и междисциплинарно, однако важнейшим фокусом гуманитарного метода выдающегося мыслителя выступает идея диалога: «Все в жизни диалог - то есть диалогическая противоположность [Бахтин 1979a, 75].

Диалог в творчестве М.М. Бахтина имеет «всеобщее» значение, однако можно выделить основные его качества. Во-первых, он является основой человеческого взаимопонимания. Диалогизм для Бахтина - это «доверие к чужому слову, благоговейное приятие (авторитетное слово), ученичество, поиски и вынуждение глубинного смысла, согласие, его бесконечные градации и оттенки (но не логические ограничения и не чисто предметные оговорки), наслаивания смысла на смысл, голоса на голос, усиление путем слияния (но не отождествления), сочетание многих голосов (коридор голосов), дополняющее понимание, выход за пределы понимаемого и т. п. Эти особые отношения нельзя свести ни к чисто логическим, ни к чисто предметным. Здесь встречаются целостные позиции, целостные личности» [Бахтин 1979б, 300].

Во-вторых, диалог, по М.М. Бахтину, возникает только в узловых моментах истории и развития культуры, поэтому он уникален в своих духовных и исторических особенностях и одновременно универсален: «Диалогическое проникновение обязательно в филологии (ведь без него невозможно никакое понимание): оно раскрывает новые моменты в слове (смысловые в широком смысле), которые, будучи раскрыты диалогическим путем, затем овеществляются. Всякому продвижению науки о слове предшествует ее "гениальная стадия" обостренно диалогическое отношение к слову» [Бахтин 1979а, 59].

Кроме того, диалог выступает основой всех речевых жанров, которые, по мнению
Бахтина, представляют собой сконцентрированную в знаке историческую память «перешедших на уровень автоматизма значений и смыслов. ...Жанр - это представитель культурно-исторической памяти в процессе всей идеологической деятельности... (летописи, юридические документы, хроники, научные тексты, бытовые тексты: приказ, брань, жалоба, похвала и т. д.)» [Бахтин 1979б, 102].

Диалог у М.М. Бахтина представляет собой актуальный и потенциально бесконечный и незавершимый процесс, некое «живое» событие бытия. Отметим, что процессуальность диалога определена устремленностью человека к творческому развитию и экзистенциальной открытостью к бытию. Диалог вневременен, внесюжетен. В.С. Библер отмечает: «Реально диалог культур совершается в работах М.М. Бахтина не в “лакуне" между культурами, не на “ничьей земле", где эти культуры как бы заново и впервые становятся, возникают, но - только внутри определенной культуры, - культуры нововременной, культуры романного слова, на площадке идеологически и диалектно - преднайденного диалога» [Библер 1991, 121].

Таким образом, можно говорить о том, что диалог личностей и диалог культур - понятия взаимозаменяющие и взаимодополняющие, как макрокосм и микрокосм. «В каждом слове звучал ... спор (микродиалог) и слышались отголоски большого диалога» [Библер 1990, 19].

Культуры как квазиличности диалога характеризуются, по мнению М.М. Бахтина, во-первых, «вненаходимостью» - неповторимостью и уникальностью личностных позиций участников диалога, их обусловленностью конкретным социокультурным контекстом [Богуславская 2011]; во-вторых, безграничностью: «Внутренней территории у культурной области нет: она вся расположена на границах, границы проходят повсюду, через каждый момент ее, систематическое единство культуры уходит в атомы культурной жизни, как солнце отражается в каждой капле ее. Каждый культурный акт существенно живет на границах...» [Бахтин 1975, 25]; в-третьих, сознательной ответственностью в каждой диалогической позиции (по Бахтину - «не алиби в бытии»). Для культур это отношения непрекращающегося интереса друг к другу. 
Основой и способом ведения диалога в теории Бахтина является текст, представленный в форме различных знаковых систем (речь произносимая; речь запечатленная; знаковая система). Одной из них является искусство (произведение искусства): «Любой продукт человеческого творчества своего рода “послание"; он по-своему “говорит", вопрошает и отвечает, несет в себе "весть", которую нужно уметь “услышать" и которая, соприкасаясь с другим текстом, вновь и вновь актуализируется в целостной жизни культуры» [Бахтин 1975, 115].

Любой текст, по Бахтину, должен основываться на предшествующих текстах, которые были созданы авторами с особенным уникальным мировосприятием и собственным образом мира. М.М. Бахтин в книге «Эстетика словесного творчества» отмечал тот факт, что человека можно анализировать и изучать только через создаваемые им или созданные тексты (произведения искусства). «Любой текст строится как мозаика цитаций, любой текст есть продукт впитывания и трансформации какогонибудь другого текста. Тем самым на место понятия интерсубъективности встает понятие интертекстуальности...», - отмечает Бахтин [Бахтин 1975, 41]. Таким образом, текст, вмещая все прошлые и будущие культурные смыслы, становится мостом между разнообразными традициями, он диалогичен и всегда направлен к Другому. Текст близок понятию произведения, которое выступает целостным бытием автора, отстраненным от него и имеющим смысл только при наличии адресата, и коммуникативного взаимодействия между автором и читателем. По словам В.С. Библера: «Все его (текста. $-A$. $B$.) содержание только в нем, и все его содержание - вне его, только на его границах, в его небытии как текста» [Библер 1991, 76]. Данное взаимодействие - диалог - создает новый, уникальный мир.

Основным условием, при котором текст становится произведением, является его понятность другим при погружении двух субъектов диалога в культурный контекст. Для того чтобы быть понятым, текст должен обладать понятными контекстами и внутренней логикой смыслов, заложенных в нем, а также быть выстроенным в общей жанровой и языковой традиции данной культуры.
Понимание по Бахтину - это всегда совокупность самопознания (общение с самим собой), общения (с Другим) и взаимопонимания. Мыслитель противопоставляет понимание объяснению: в последнем только одно сознание, а значит один субъект, в случае понимания - два. Понимание произведения влечет за собой осознание смысла бытия личности в контексте культуры в сочетании с его особенным вниманием и общением с Другим. «Смысл не может (и не хочет) менять физические, материальные и другие явления, он не может действовать как материальная сила. Да он и не нуждается в этом: он сам сильнее всякой силы, он меняет тотальный смысл события и действительности...» [Бахтин 1979б, 37].

Одной из центральных проблем, рассматриваемых М.М. Бахтиным, является идея творчества, которая представлена как «концепция человека как субъекта культуры: категорией творчества $<$...> обозначается способ представленности человека в культуре, или, точнее, способ жизни человека в культуре» [Бахтин 1979б, 111]. Творчество в контексте жизни и исторического развития культур это процесс создания текстов или произведений, являющихся продуктом духовной активности человека и несущих в себе те или иные смыслы. Любой созданный текст имеет адресата, он может быть направлен к Другому или к самому себе.

Особенностью творчества как духовной обогащенной энергии является его нематериальная сущность. Творчество - это личностная активность и переход к другому значению. При этом технические характеристики созданной вещи или объекта абсолютно не важны окружающая среда выступает лишь промежуточным звеном. «Вместе с тем реализация духовного в разных сферах деятельности человека не уничтожает его специфики. Так, будь то Восток или Запад, религия, философия или искусство, несмотря на все многообразие форм проявления и понимания, духовное содержит в себе нечто сущностно единое, которое вытекает из положения человека в мире, какой бы культуре или духовной традиции он ни принадлежал» [Нижников 2019, 158].

Смысл в концепции творчества, по M.М. Бахтину, является ответом на личностный духовный запрос и может быть понятым 
лишь той личностью, которая задает вопросы и ищет ответы: «Идея начинает жить, то есть формироваться, развиваться, находить и обновлять свое словесное выражение, порождать новые идеи, только вступая в существенные диалогические отношения с другими чужими идеями» [Бахтин 1979а, 67].

Различные культуры согласно концепции Бахтина находятся в постоянном диалоге и взаимодействии, дополняя друг друга. Любой виток развития культуры не происходит обособленно - становлению уникальности способствует ее обогащение посредством других культур в процессе диалогических отношений, которые представляют собой «почти универсальное явление, пронизывающее всю человеческую речь и все отношения и проявления человеческой жизни, вообще все, что имеет смысл и значение. <.. > Где начинается сознание, там < ..> начинается и диалог» [Бахтин 1979б, 58]. Диалог между разными культурами неизбежен, однако он может возникнуть только при соблюдении трех условий: равенства культур, уважения к чужой культуре и признания права каждой культуры на отличия.

Разрабатывая методологию диалога культур, Бахтин акцентирует внимание на том, что диалог - это всегда развитие. Все великие культурные явления появляются исключительно в узле пересечения различных культур в процессе коммуникации. Каждая культура обращена к другой культуре, она задает вопросы и ждет ответов, она готова осваивать достижения другой культуры, так как это основа ее жизни: «Чужая культура только в глазах другой культуры раскрывает себя полнее и глубже... Один смысл раскрывает свои глубины, встретившись и соприкоснувшись с другим, чужим смыслом..., между ними начинается как бы диалог, который преодолевает замкнутость и односторонность этих смыслов, этих культур... При такой диалогической встрече двух культур они не сливаются и не смешиваются, но они взаимно обогащаются» [Бахтин 1979б, 335].

Диалог культур - это безусловная потребность во взаимодействии, которое нельзя себе представить без наличия интереса, взаимопонимания и при условии полного сохранения индивидуальности каждой из культур в процессе коммуникации: «Взаимопонимание столетий и тысячелетий, народов, наций и культур обеспечивает сложное единство всего человечества, всех человеческих культур (сложное единство человеческой культуры)» [Бахтин 1979б, 390].

Для плодотворного взаимовлияния различных культур необходима реализация таких условий, как нахождение общих культурных кодов, возникновение (при отсутствии) общего ментального пласта, уважение к чужой культуре при проникновении в ее систему ценностей, преодоление множества стереотипов. Кроме того, понимание культуры как диалога предполагает общение с собой как с Другим. Бахтин, а в дальнейшем и Библер, продолживший развитие его идей, пришли к важному выводу: без диалога с самим собой рефлексия невозможна. Вследствие самопознания и способности соотнести себя с Другим появляется возможность межкультурного диалога.

\section{О теории диалога культур в диалогике В.С. Библера}

В культуре человек всегда подобен Богу в афоризме Поля Валери: «Бог сотворил мир из ничего, но материал все время чувствуется». Вне этой трагедии и иронии культура невозможна; всякий разговор о культуре становится пустышкой и риторикой.

В.С. Библер

Бахтин стал первым, кто в отечественных исследованиях культуры затронул тему диалога и диалога культур в своих работах, посвященных этическим и эстетическим проблемам. Научные и философские изыскания ученого продолжил его последователь - Владимир Соломонович Библер, который более тридцати лет вел теоретический семинар по проблемам философской логики и философии культуры - «Диалогика культуры».

Вслед за Бахтиным, который, анализируя произведения искусства, пришел к выводу о том, что образы культуры одновременны, равноценны и находятся во взаимодействии, Библер расширяет это положение и ос- 


\section{НАУЧНЫЕ СООБЩЕНИЯ}

паривает гегелевскую теорию «снятия» философских систем по ходу развития. Основываясь на примерах не только философии, но искусства и нравственности как форм бытия внутри понятия культуры, он предлагает два возможных схематизма «исторической наследственности».

Первый из них представляет собой «восхождение по лестнице “прогресса"» с преодоленными ступенями. Каждая новая ступень является подготовительной формой последующей, которая, в свою очередь, вбирает все положительное и является более высокой по сравнению с предыдущей. «В этом восхождении все предшествующее: знание, старые орудия труда, пережившие себя “формации”... - конечно, не исчезают "в никуда", они "уплотняются”, “снимаются”, перестраиваются, теряют свое собственное бытие в знании и умении высшем, более истинном, более систематизированном...» [Библер 1989, 33]. Такой схематизм характерен для науки и ориентированной на нее философии - наукоучения. Библер приводит пример с механикой и математикой: никто не будет изучать эти дисциплины по трудам Галилея, Ньютона или Эвклида. Все предыдущие знания и открытия уплотнены и преподносятся в упрощенной форме.

Вторая форма - схематизм «драматического произведения» («Явление четвертое... Те же и Софья») - характерна для искусства, нравственности, философии (не следующей принципам восхождения и снятия) и, по мнению Библера, культуры в целом. В данном случае все прежние структуры не исчезают, сохраняют свое значение, обнаруживая все новые черты при взаимодействии с другими структурами. На пересечении их взаимодействия рождается диалог - «схематизм общения (не обобщения) различных всеобщих и уникальных форм бытия» [Библер 1989, 37]. Шекспир с Софоклом вступают во взаимообратный диалог независимо от пространства, времени и того, кто творил раньше или позже, ибо в искусстве эти понятия соотносительны и одновременны. В этом же диалоге и в тот же самый момент принимает участие и читатель (зритель).

Библер призывает нас и науку понимать и развивать именно как феномен культуры, то есть по схематизму общения, и рассматри- вать научные парадигмы с ракурса одновременности и взаимного перехода. Внутри культуры такие формы ее бытия, как искусство, нравственность, философия, наука, также вступают во взаимодействие и диалог.

Рассмотрим понятие культуры, которая, в понимании В.С. Библера, «пронизывает... все решающие события жизни и сознание людей нашего века» [Библер 1990, 261]. Культуру, по мнению ученого, можно определить тремя взаимодополняющими и взаимосвязанными дефинициями. Во-первых, это культура как способ самоопределения личности, которой присущи социальность и историчность: «Культура - это форма самодетерминации индивида в горизонте личности, форма самодетерминации нашей жизни, сознания, мышления; то есть культура - это форма свободного решения и перерешения своей судьбы в сознании ее исторической и всеобщей ответственности» [Библер 1989, 33]. Во-вторых, культура как «мир впервые». Основанием культуры является произведение, через которое происходит коммуникация личностей вне времени и пространства. «Культура в своих произведениях позволяет нам - автору и читателю как бы заново порождать мир, бытие предметов, людей, свое собственное бытие» (там же. - A. B.). И, наконец, в-третьих, культура как форма диалога, коммуникации людей различных культурных традиций вне временных и пространственных рамок. «Культура есть форма одновременного бытия и общения людей различных - прошлых, настоящих и будущих - культур, форма диалога и взаимопорождения этих культур» [Библер 1989, 32]. В соответствии с теорией Бахтина любое проявление культуры обусловлено ее общением с любой другой культурой: «Культура есть там, где есть две (как минимум) культуры... самосознание культуры есть форма ее бытия на грани с иной культурой» [Библер 1991, 85].

В.С. Библер, в свою очередь, пытается предостеречь от примитивного понимания диалога как вида речевой деятельности человека, разделяющегося на различные подвиды: научный, бытовой, моральный и т. д. Данное понимание диалога не имеет отношения к диалоговой концепции культуры: «В “диалоге культур" речь идет о диалогичности самой истины (...красоты, добра...), о том, что по- 
нимание другого человека предполагает взаимопонимание "Я - ты" как онтологически различных личностей, обладающих - актуально или потенциально - различными культурами, логиками мышления, различными смыслами истины, красоты, добра... Диалог, понимаемый в идее культуры, - это не диалог различных мнений или представлений, это - всегда диалог различных культур» [Библер 1990, 299].

Кроме того, диалог культур обладает следующими отличительными чертами: 1) в диалоге нет времени, но всегда есть момент, следовательно, он происходит только в настоящем; 2) амбивалентность диалога культур характеризуется территориальной незакрепленностью (диалог, как и культура по Бахтину, «собственной территории не имеет»), потому что адресован вовне, к другой культуpe, в совокупности с напряженным обращением вглубь и внутрь себя самой. «Каждая культура есть некий “двуликий Янус”» [Библер 1989, 37]; 3) формой общения в диалоге культуры является произведение (по Бахтину - текст), которое также является формой общения, но уже «личностей как (потенциально) различных культур». Произведение воплощает собственное бытие личности (автора, «Я»), и оно всегда адресовано другой личности (читателю, Ты), однако внутри «Я» происходит как общение с alter ego. Именно при таком взаимодействии творца и читателя (Я и Ты) мир рождается заново (у Бахтина «мир впервые»). Произведение, с одной стороны, замкнуто, но с другой - всегда открыто для довершения читателем (зрителем, слушателем, Тобой).

Таким образом, произведение - это диалог в диалоге: «Понимание произведения как феномена культуры и понимание культуры как сферы произведений: два эти понимания “подпирают” и углубляют друг друга» [Библер 1989, 38].

В своих трудах Библер акцентирует внимание на важном переходе, произошедшем в конце XX в., от науки логики, которая процветала в Новое время, к культуре логики, которая характеризирует современность.

Логика логична только тогда, когда она является началом последующей логики. В точке этого перехода рождается диалог: «Логика начала логики означает предположе- ние многих разумов, многих всеобщих логик, логически извечных и реализуемых только в диалоге между собой» [Библер 1990, 387], сосуществующих одновременно и связанных друг с другом в месте их общего начала. Логика, при которой происходит превращение одной в другую, где они задают друг другу вопросы и одновременно отвечают на них, то есть существуют в диалоге, и становится логикой культуры. Основной целью ее является понимание и актуализация бытия как произведения культуры.

Культура логики, диалогика или философская логика диалога культур - оригинальная концепция, созданная Библером на основании расширения и углубления теоретических находок М.М. Бахтина. Начав с предположения о неснимаемости различных структур в «Органоне» культуры, Библер вывел логичную концепцию взаимопревращения и взаимообщения этих структур.

$$
* * *
$$

Подводя итоги, стоит отметить масштабы расширения проблематики диалога культур В.С. Библером, которые, к сожалению, преуменьшаются некоторыми исследователями и сводятся исключительно к идее диалога философских парадигм, встречающихся «как бы впервые».

Безусловно, общая идея диалога объединяет философские концепции Бахтина и Библера, однако последний, основываясь на теории Бахтина и расширяя ее идеи, создал собственную оригинальную концепцию решения важнейших проблем философской мысли.

Библер назвал свою книгу, посвященную великому русскому философу, «М.М. Бахтин, или Поэтика культуры», очень точно акцентируя внимание на гуманитарной направленности научных изысканий своего учителя, ведь поэтика - литературоведческая наука: «Предмет гуманитарных наук - выразительное и говорящее бытие. Это бытие никогда не совпадает с самим собой и потому неисчерпаемо в своем смысле и значении... <..> бытие выражения двусторонне: оно осуществляется только во взаимодействии двух сознаний (я и другого); взаимопроникновение с сохранением дистанции; это - поле встречи двух созна- 
ний, зона их внутреннего контакта» [Бахтин 2000, 228-229]. И, будучи единодушным с бахтинским пониманием идеи диалога как формы бытия культуры и взаимной коммуникации культур, он приходит к выводу, что реальный диалог культур у Бахтина может осуществляться только в системе одной идеи культуры - «культуры романного слова, на площадке идеологически - и диалектно - преднайденного диалога» [Библер 1991, 67].

Библер же называет свою теорию философской логикой культуры, расширяя границы функционирования диалога и вводя его не только в сознание, но и в мышление. Таким образом, философ говорит о том, что культура есть форма познавательной деятельности, которая присуща человеку. И здесь же важны собственные, отличные от концепции Бахтина, идеи Библера о том, что культура - это самодетерминация и самоопределение индивида в горизонте личности: «Жизнь индивида всегда осуществляется... в возможности совершить невозможное, самопредопределить свою судьбу. И - в отличие от "падающего тела" - человек свободен совершать невозможное. Не каждый - художник или философ. Но работа сознания каждого человека происходит в стремлении самому обосновать начала своего мышления; в стремлении сосредоточить свою судьбу в мгновение свободных решений... То есть - происходит в сопряжении основных идей “исторической поэтики” и “философской логики”» [Библер 1990, 358].

Резюмируя вышеизложенное, отметим, что культура по Библеру - это жизнь личности, ее духовный мир, отделенный от нее и транслированный в произведение, способный существовать и после физической смерти данной личности в жизни людей последующих эпох и иных устремлений: «Отвечая на вопрос: “Что есть культура?", - мы всегда - до конца сознавая это или нет - отвечаем на другой вопрос: "В какой форме можем существовать - и развивать себя - мой дух, и моя плоть, и мое общение, и насущная - в моей жизни жизнь близких людей после моей (моей цивилизации) гибели, “ухода в нет”?.. Ответ - в форме культуры» [Библер 1990, 82]. Таким образом, культура и диалог культур согласно теории Библера могут также являться и способом преодоления конечности бытия.

\section{СПИСОК ЛИТЕРАТУРЫ}

Бахтин 1975 - Бахтин М.М. Вопросы литературы и эстетики. М.: Худож. лит., 1975.

Бахтин 1979а - Бахтин М.М. Проблемы поэтики Достоевского. М.: Сов. Россия, 1979.

Бахтин 19796 - Бахтин М.М. Эстетика словесного творчества. М.: Искусство, 1979.

Бахтин 2000 - Бахтин М.М. Автор и герой. К философским основам гуманитарных наук. СПб.: Азбука, 2000.

Библер 1989 - Библер В.С. Культура. Диалог культур (опыт определения). Вопросы философии. 1989. № 6. С. 31-42.

Библер 1990 - Библер В.С. От наукоучения - к логике культуры: Два философских введения в двадцать первый век. М.: Политиздат, 1990.

Библер 1991 - Библер В.С. Михаил Михайлович Бахтин, или Поэтика культуры. М.: Прогресс, 1991.

Богуславская 2011 - Богуславская С.М. Диалог в трудах М.М. Бахтина. Вестник ОГУ. 2011. № 7 (126). C. 17-23.

Левинас 2000 - Левинас Э. Тотальность и бесконечное. СПб. : Унив. кн., 2000.

Левинас 2006 - Левинас Э. Забота о добре // Путь к Другому. СПб.: Изд-во Санкт-Петербург. унта, 2006.

Нижников 2019 - Нижников С.А. Духовные основания диалога культур // Высшая школа: опыт, проблемы, перспективы: материалы XII Междунар. науч.-практ. конф.: в 2 ч. (г. Москва, 28-29 марта 2019 г.). М.: РУДН, 2019. Ч. 2. C. $157-162$.

Сартр 2000 - Сартр Ж.-П. Бытие и ничто. М.: Республика, 2000.

\section{REFERENCES}

Bakhtin M.M., 1975. Questions of Literature and Aesthetics. Moscow, Hudozh. lit.

Bakhtin M.M., 1979. Problems of Dostoevsky's Poetics. Moscow, Sov. Rossija.

Bakhtin M.M., 1979. Aesthetics of Verbal Creativity. Moscow, Iskusstvo.

Bakhtin M.M., 2000. On the Philosophical Foundations of the Humanities. SaintPetersburg, Azbuka.

Bibler V.S., 1989. The Dialogue of Cultures (Experience). Voprosy filosofii, no. 6, pp. 31-42.

Bibler V.S., 1990. From Science to the Logic of Culture: Two Philosophical Introduction to the TwentyFirst Century. Moscow, Politizdat.

Bibler V.S., 1991. Mikhail Mikhailovich Bakhtin, Or the Poetics of Culture. Moscow, Progress. 
А.А. Волкова. Философское понимание диалога культур в концепциях М.М. Бахтина и В.С. Библера

Boguslavskaya S.M., 2011. Dialogue in the Writings of M.M. Bakhtin. Vestnik $O G U$, no. 7 (126), pp. $17-23$

Levinas E., 2000. Totality and the Infinite. Saint Petersburg, Univ. kn.

Levinas E., 2006. Path to Another. Saint Petersburg, Izd-vo Sankt-Peterburg. un-ta.
Nizhnikov S.A., 2019. Spiritual Foundations of Cultural Dialogue. Vysshaya shkola: opyt, problemy, perspektivy: materialy XII Mezhdunar. nauch.prakt. konf.: in 2 pt. Pt. 2. Moscow, RUDN, pp. 157-162.

Sartr Zh.-P., 2000. Being and Nothing. Moscow, Respublika.

\section{Information About the Author}

Anastasia A. Volkova, Chief Methodologist, "Universarium" Distance Education Inter-University Platform (LLC "Kursarium"), Ostapovsky pas., 3, 109316 Moscow, Russian Federation; Applicant, Department of "History of Philosophy", Peoples Friendship University of Russia, Miklukho-Maklaya St., 6, 117198 Moscow, Russian Federation, dead-ligeya@mail.ru, https://orcid.org/0000-0002-3283-4603

\section{Информация об авторе}

Анастасия Алексеевна Волкова, главный методист, Дистанционная образовательная межуниверситетская площадка «Универсариум» (ООО «Курсариум»), Остаповский проезд, 3, 109316 г. Москва, Российская Федерация; соискатель кафедры «История философии», Российский университет дружбы народов, ул. Миклухо-Маклая, 6, 117198 г. Москва, Российская Федерация, dead-ligeya@mail.ru,https://orcid.org/0000-0002-3283-4603 